\title{
REFLEXÕES SOBRE LÍNGUA E INTERCULTURALIDADE EM UMA ESCOLA DA FRONTEIRA BRASIL/VENEZUELA
}

\section{REFLECTIONS ON LANGUAGE AND INTERCULTURALITY IN ASCHOOL IN THE BORDER BETWEEN BRAZIL AND VENEZUELA}

\author{
Cora Elena Gonzalo Zambrano*
}

\begin{abstract}
Resumo: O objetivo geral deste artigo foi discutir como é o relacionamento entre docentes e discentes em sala de aula com crianças de diferentes línguas e culturas. Para isso, foi realizado um estudo de caso com crianças de 5 e 6 anos de idade, estudantes do nível Jardim II, em uma escola brasileira na fronteira do Brasil com a Venezuela. O problema de pesquisa é o ambiente escolar bilíngue e transcultural do grupo em questão. Após a pesquisa bibliográfica e de campo, com análise qualitativa, os resultados destacam a importância da educação intercultural para uma efetiva interação entre grupos diferentes, mostrando que a relação entre docentes e discentes na referida escola ainda é de imposição da cultura dominante.
\end{abstract}

Palavras chave: Transculturalidade. Interculturalidade. Escola. Fronteira.

\begin{abstract}
The general objective of this article was to discuss how the relationship between teachers and students in the classroom with children of different languages and cultures. For that, a case study was carried out with children of 5 and 6 years of age, students of the Jardim II level, in a Brazilian school on the border of Brazil and Venezuela. The research problem is the bilingual and transcultural school environment of the group in question. After bibliographic and field research, with qualitative analyze, the results highlight the importance of intercultural education for an effective interaction between different groups, showing that the relationship between teachers and students in this school is still imposed by culture dominant.
\end{abstract}

Keywords: Transculturality. Interculturality. School. Border

\section{Introdução}

As relações entre pessoas de diferentes línguas e culturas sempre são complexas, como afirma Fleuri (2003, p. 11):

\begin{abstract}
A complexidade da relação entre culturas evidencia a necessidade de analisar a abordagem da existência de uma fronteira cultural, uma borda deslizante e intervalar nas relações, para além de uma simples divisão e classificação binária da existência humana. Esse espaço intervalar da cultura aparece como um espaço da intervenção (tensão-negociação-tradução) que introduz a reinvenção criativa da existência, fundada num profundo desejo de solidariedade social: a busca do encontro. (FLEURI, 2003, p.11)
\end{abstract}

Essa complexa relação entre as culturas é bem visível nas cidades gêmeas Pacaraima/Brasil e Santa Elena de Uairén/Venezuela, em constante "tensão, negociação e tradução". O município brasileiro de Pacaraima, localizado na faixa de fronteira com a Venezuela, a 215 quilômetros de Boa Vista, capital de Roraima, fica a aproximadamente 15 quilômetros de distância da cidade de Santa Elena de Uairén, na Venezuela. A população dessa região vive num contexto de identidade cultural híbrida, devido ao grande contato entre ambas as nações.

\footnotetext{
* Professora da Universidade Estadual de Roraima. Pesquisadora na área de Linguística Aplicada, especificamente escolarização em contexto bilingue de fronteira, linguagem e identidade e ensino de línguas. Especialista em metodologia do ensino de línguas. Mestre em Letras pela Universidade Federal de Roraima. Coordenadora da Especialização em Ensino de Línguas em Contexto de diversidade linguística. coragonzalo@gmail.com
} 
Para Sturza (2010, p.84) a questão das línguas nas fronteiras traz para a discussão não apenas a geografia como determinante das relações, mas os sujeitos políticos e históricos que residem nela, "[...] que circulam e se mobilizam nas bordas de uma linha imaginária que divide territórios. Linha esta que lhes permite moverse e volver ${ }^{l}$. Esse movimento tem colocado a língua portuguesa e espanhola em relação". Ou seja, os moradores dessa região estão em constante trânsito, indo e voltando, atravessando a fronteira e usando as duas línguas.

Lagares (2010, p. 129) afirma que as fronteiras linguísticas não coincidem com as fronteiras políticas:

[...] o recorte feito sobre um território impõe sempre diferentes organizações das falas, de acordo com modelos que são erigidos pelos poderes políticos e econômicos dominantes em cada área. Pode acontecer, nesse sentido, que uma língua pule as barreiras da fronteira política nas falas cotidianas das pessoas que circulam nesse espaço intermediário sem se reconhecerem, mutuamente, de ouvido, como fazendo parte de um lado ou do outro. (LAGARES, 2010, p.129).

Como o autor explica, uma língua pode pular a barreira da fronteira política, como fica claro no contexto analisado. A proximidade linguística entre o português e o espanhol gera uma facilidade de comunicação na fronteira e a proximidade geográfica incentiva $o$ contato cultural. Brasileiros e venezuelanos, moradores da região, constantemente estão expostos à língua dos vizinhos através de diversos meios, como as emissoras de rádio de Santa Elena que têm alcance em território brasileiro, assim como, os programas de rádio destinados aos brasileiros, pois, em Pacaraima não tem esse meio de comunicação, muitos usam as ondas das rádios venezuelanas para veicular notícias e músicas brasileiras, sendo constante o uso dos dois idiomas.

De acordo com Sturza (2010, p. 94):

[...] a fronteira, concebida do ponto de vista mais social que geopolítico, é notadamente um espaço de confluências, sejam elas por integração, sejam elas por oposição de todo tipo, política, ideológica, econômico-social. (STURZA, 2010, p. 94)

Para retratar essa integração que a autora cita, destaco também os brasileiros que trabalhavam no comércio venezuelano ou têm familiares e amigos na cidade vizinha, ainda há aqueles que trabalham na área da saúde no Brasil e recebem diariamente os pacientes venezuelanos. Os pacaraimenses também procuram atendimento no sistema de saúde de Santa Elena, apesar da grande crise econômica e da carência de especialistas, na cidade vizinha há oftalmologistas cubanos que atendem pelo convênio da Venezuela com o país caribenho. Por outro lado, os venezuelanos usam o sistema de saúde brasileiro, como hospitais e postos de saúde, até para acompanhamento pré-natal e vacinação. Segundo o diretor do hospital de Pacaraima, mais da metade dos atendimentos registrados na unidade, são de cidadãos venezuelanos.

É comum encontrar na região de fronteira casamentos entre venezuelanos e brasileiros, que formam famílias híbridas, cujos filhos se tornam naturalmente bilíngues

\footnotetext{
${ }^{1}$ Mover-se e Voltar, tradução minha.
} 
e assumem uma identidade transcultural ${ }^{2}$. Também é possível encontrar em Santa Elena famílias inteiras de brasileiros que residem lá há mais de 30 anos por oportunidade de trabalho nos garimpos ou na compra de ouro e diamante na fronteira. Até alguns anos atrás outras famílias brasileiras que moravam em Pacaraima optavam por fixar residência em Santa Elena, mesmo trabalhando no Brasil, por ter um menor custo de vida. Gasolina, energia elétrica, gás de cozinha, móveis e gêneros alimentícios mais baratos, eram os fatores que pesavam na decisão dessas pessoas. Hoje, com o agravamento da crise política e social venezuelana, os brasileiros estão retornando ao país natal e milhares de venezuelanos cruzam a fronteira em busca de melhores condições de vida.

No âmbito escolar é enorme a demanda de venezuelanos por vagas nas escolas de Pacaraima. Há alguns anos vem crescendo o número de estudantes cujos pais preferem que os filhos estudem do lado brasileiro, o que gerou salas de aulas mistas, com alunos brasileiros e venezuelanos, além de outras nacionalidades como colombianos, peruanos e, ainda, tem os estudantes brasileiros que moram em Santa Elena e todos os dias vêm ao seu próprio país para estudar.

Nesse sentido, problematizei o ambiente escolar bilíngue e transcultural do grupo em questão, com a seguinte pergunta: De que maneira crianças brasileiras, venezuelanas e de dupla nacionalidade, moradoras da região de fronteira, se inserem nas atividades escolares?

Este artigo é um recorte de um trabalho maior ${ }^{3}$, cujo objetivo geral foi discutir como é o relacionamento entre docentes e discentes em uma sala de aula com crianças de diferentes línguas e culturas. Para isso, foi realizado um estudo de caso com crianças de 4 a 6 anos de idade, estudantes do nível Jardim II, em uma escola de Pacaraima.

\section{Língua, identidade e transculturalidade}

Quando penso em língua a imagino como algo líquido e nunca como sólido, assim como afirmam Cox e Assis Peterson (2007, p. 42), já que a língua muda, está em constante transformação ou trânsito, no "debordamento de fronteiras entre as línguas". Na prática, não existe fronteira entre as línguas, elas vão se transformando e adaptando conforme a necessidade de comunicação. Nas regiões de fronteira as línguas transitam assim como as pessoas, de um país ao outro, de uma cultura à outra.

De acordo com Rajagopalan (2003), as línguas não são "meros instrumentos de comunicação", são a extensão das identidades. Segundo ele, quem transita em diversos idiomas está redefinindo sua própria identidade. Para Hall (2006), a identidade é formada na interação entre o eu e a sociedade. $\mathrm{O}$ "eu real" é formado e modificado com os mundos culturais exteriores e as identidades que esses mundos oferecem. Assim, o sujeito do iluminismo, que tinha uma única identidade, se torna composto por várias e pode assumir diferentes identidades em diferentes momentos, transformando-se no sujeito pósmoderno, fragmentado, cujas identidades podem ser contraditórias, indo em diferentes direções.

Para Freitas (2008) a língua é um dos elementos mais apontados como característica de identidade, concordando com Rajagopalan (1998) quando afirma que a identidade de um indivíduo se constrói na língua e através dela, por esse motivo, as identidades estão sempre em estado de transformação.

\footnotetext{
${ }^{2} \mathrm{O}$ termo transculturalidade (BORTONI-RICARDO, 2007) é usado com a intenção de desnaturalizar as questões de hegemonia cultural, sendo o radical "trans" visto como portador do sentido de movimento multi e bidireccional, ou seja, várias culturas que transitam, se movimentam entre determinados grupos sociais.

${ }^{3}$ Dissertação de mestrado, ver Zambrano (2016).
} 
Da mesma forma em que afirmo que a língua está em trânsito, as culturas também. Por esse motivo adoto o termo transculturalidade, tal como usado por Cox e Assis Peterson e Bortoni-Ricardo. A ideia é de movimento de ir e vir, exatamente como acontece na fronteira Brasil/Venezuela, na qual as crianças transitam nos dois países, nas duas línguas e nas duas culturas. Segundo Hall (2006) as pessoas não apagam seus vínculos quando se deslocam, mas também não vivem em um continente culturalmente unificado.

\section{Diversidade e escola}

No contexto da diversidade linguística e cultural, a diferença e a identidade tornam-se algo natural, nesses casos, o respeito e a tolerância são as palavras de ordem. Porém, para Silva (2009, p. 96) é necessário que a diferença e a identidade sejam vistas como processos de produção social que envolvem relações de poder:

Ver a identidade e a diferença como uma questão de produção significa tratar as relações entre as diferentes culturas não como uma questão de consenso, de diálogo ou comunicação, mas como uma questão que envolve, fundamentalmente, relações de poder. (SILVA, 2009, p. 96)

Dessa forma, é necessário entender que identidade e diferença são elementos passivos da cultura, que são constantemente criados e recriados. Para a pedagogia e os currículos escolares o outro cultural é sempre um problema, que questiona a própria identidade. Para o autor supracitado, isso é um problema pedagógico e curricular, não apenas porque as crianças e os jovens são obrigados a interagir com o outro no espaço escolar, e sim, porque a diferença não deixa de ser preocupante, apesar de muitas vezes ser ignorada e reprimida, gerando conflitos e até mesmo violência.

O resultado desse contato seria, segundo Silva (2009, p.98), “[...] novas dicotomias, como as do dominante tolerante e do dominado tolerado ou a da identidade hegemônica, mas benevolente e da identidade subalterna, mas respeitada". Dessa maneira, o autor traz a discussão sobre a sociedade dominante que não impõe diretamente a língua e a cultura, mas mostra a hegemonia dela, da mesma forma que o "dominado" acredita ser respeitado.

Bauman (1998) chama de estranhas as pessoas que não se encaixam no mapa cognitivo, moral ou estético. Nesse caso da escola, os diferentes, seriam os estranhos de Bauman, para ele, todas as sociedades produzem seus estranhos. Mas cada espécie de sociedade produz sua própria espécie de estranho, e os produz de sua própria maneira, inimitável.

A estratégia comumente adotada na rotina pedagógica das escolas é apresentar aos estudantes uma visão superficial das diferentes culturas, mostrando o diferente como exótico e curioso. Para considerar as contribuições da teoria cultural recente, seria necessária uma abordagem onde a pedagogia e o currículo tratassem a identidade e a diferença como questão política, perguntando sempre como a identidade e a diferença são produzidas e por meio de qual instituição. Essa estratégia deve admitir o fato da diversidade tornar-se incapaz de fornecer os instrumentos para questionar os mecanismos e as instituições que fixam as pessoas em determinadas identidades culturais e que as separam por meio da diferença. (SILVA, 2009, p.99-100).

De acordo com Bauman (1998) o projeto liberal da modernidade admite que as pessoas são diferentes, mas diferentes por causa da diversidade das tradições locais e particularistas em que elas crescem e amadurecem. "São produtos da educação, criaturas da cultura e, por isso, flexíveis e dóceis a serem transformadas [...]" (BAUMAN, 1998, 
p.29). Nesse sentido, por meio da educação escolar, esses alunos "diferentes" ou "estranhos" podem ser transformados.

Moita Lopes (2002, p.16) afirma que a escola é um espaço privilegiado para a (re) construção da identidade, pois "[...]é na escola que em geral a criança se expõe, pela primeira vez, às diferenças que nos constituem e que, portanto, representam as primeiras ameaças ao mundo da família”. Essas ameaças seriam, entre outras coisas, deixar um pouco de lado a cultura familiar, nesse caso minoritária, e adotar a cultura majoritária, que estão aprendendo na escola.

Contudo, a pedagogia escolar deve sempre questionar essas relações de poder entre identidade e diferença, em vez de apenas declarar seu "respeito" com a diversidade. Dessa forma, a educação intercultural seria o mais adequado.

\section{Interculturalidade}

Para entender a interculturalidade considero a definição de Fleuri (2001), quem a vê como a maneira de ultrapassar os obstáculos culturais alheios, adotando uma multiplicidade sócio cultural que pode reconstruir identidades. Sobre a visão intercultural o autor declara que:

Emerge no contexto das lutas contra os processos crescentes de exclusão social. Surgem movimentos sociais que reconhecem o sentido e a identidade cultural de cada grupo social. Mas, ao mesmo tempo, valorizam o potencial educativo dos conflitos. E buscam desenvolver a interação e a reciprocidade entre grupos diferentes, como fator de crescimento cultural e de enriquecimento mútuo. (FLEURI, 2001, p. 113)

Dessa forma, a interculturadade seria mais do que reconhecer a identidade cultural de cada grupo social, mas conseguir interagir entre esses diferentes grupos, de forma recíproca, para um enriquecimento de todos os envolvidos. No mundo globalizado onde as culturas se misturam cada vez de forma mais acelerada, onde os alunos inconscientemente estão inseridos em culturas globalizadas, existe a inquietude de refletir na perspectiva da globalização e no papel que cumpre o professor nesse contexto. Ainda seguindo o raciocínio de Fleuri (2001.p. 113), saliento o seguinte:

[...] em nível das práticas educacionais, a perspectiva intercultural propõe novas estratégias de relação entre sujeitos e entre grupos diferentes. Busca promover a construção de identidades sociais e o reconhecimento das diferenças culturais. Mas, ao mesmo tempo, procura sustentar a relação crítica e solidária entre elas. (FLEURI, 2001, p. 113)

A relação crítica e solidária da qual fala Fleuri, parece-me ser o mais difícil de lidar nessa relação entre grupos diferentes, mesmo no atual mundo globalizado. Candau (2008) ao refletir sobre a educação intercultural, diz que o sujeito é um ponto fundamental, por ser valorizado quando entra em contato com a cultura do outro, estímulo para que um tenha interesse em conhecer a cultura do outro.

Ainda sobre a educação intercultural, Teixeira e Ribeiro (2012, p. 287) afirmam que:

No âmbito escolar, a educação intercultural vem para ampliar a visão que muitos professores concebem sobre o ensino, visão essa que está relacionada às questões sociais, bem como tudo que impede a construção de uma sociedade mais justa, igualitária e solidária. Sabe-se que jamais haverá uma sociedade igualitária, mas a educação intercultural tenta diminuir as inúmeras 
discriminações existentes no mundo global, e o espaço de ensino é um dos principais lugares para que essa mudança ocorra. (TEIXEIRA E RIBEIRO, 2012, p. 287).

A mudança deve ocorrer dentro da escola, na visão dos professores, supervisores, diretores e alunos. Esse seria o papel da educação intercultural, de ampliar as perspectivas socioculturais no âmbito escolar.

\section{Abordagens metodológicas}

Esta pesquisa na área da Linguística Aplicada, traz a preocupação com a vida social e com a necessidade de compreendê-la. Segundo Moita Lopes (2006, p. 90):

[...] isso é essencial para que o linguista aplicado possa situar seu trabalho no
mundo, em vez de ser tragado por ele ao produzir conhecimento que não
responda às questões contemporâneas em um mundo que não entende ou que
vê como separado de si como pesquisador: a separação entre teoria e prática é
o nó da questão. (MOITA LOPES, 2006, p. 90)

Dessa forma, o autor afirma que nós pesquisadores de LA devemos tentar compreender a vida social sem separar a teoria da prática, com a possibilidade de experimentar a vida dos outros por meio das pesquisas, saindo um pouco do nosso mundo e das nossas certezas. Além disso, outra preocupação desse tipo de pesquisa é ter uma visão do conhecimento que transite por várias áreas, com o objetivo de integrá-las.

Nessa perspectiva, utilizei a pesquisa qualitativa de cunho etnográfico e interpretativista. De acordo com Bortoni- Ricardo (2008, p.34), “[...] na pesquisa qualitativa, o pesquisador está interessado em um processo que ocorre em determinado ambiente e quer saber como os atores sociais envolvidos nesse processo o percebem, ou seja: como o interpretam".

Classifico o trabalho de cunho etnográfico por fazer uso de algumas técnicas de coleta do método etnográfico, como diário de campo e observação participativa. Interpretativista por tentar interpretar as informações e ações dos sujeitos da pesquisa, aquilo que está nas entrelinhas, nos gestos, no tom de voz, etc. Como afirma Signorini (1998, p. 104) "[...] as metodologias de base interpretativista não obscurecem essa participação do pesquisador na construção do campo de referência e favorecem o não deslocamento ou purificação do linguístico". Na mesma linha de pensamento, BortoniRicardo (2008, p.32) acredita que "[...] a compreensão do observador está enraizada em seus próprios significados [...] ", sendo agente ativo na pesquisa. A mesma autora afirma que as salas de aula são espaços privilegiados para pesquisas qualitativas de base interpretativistas, como esta investigação.

A etnografia se preocupa com o significado que têm as ações e eventos para as pessoas e os grupos estudados. Alguns desses significados são expressos pela linguagem, enquanto outros são transmitidos indiretamente por meio de ações. Existe o princípio da interação constante entre o pesquisador e o objeto pesquisado, onde o pesquisador é o instrumento principal na coleta e na análise. Outra característica importante da etnografia é a ênfase no processo, no que está acontecendo e não no produto ou nos resultados finais. Sempre envolve um trabalho de campo onde o pesquisador aproxima-se de pessoas, situações, locais e eventos, mantendo um contato direto e prolongado.

Para desenvolver o trabalho foi realizado um estudo de caso com crianças de 5 e 6 anos de idade, que foram observadas durante dois anos, alunos de três turmas do nível Jardim II de uma escola brasileira localizada na fronteira do Brasil com a Venezuela. A 
instituição atende estudantes de 4 a 8 anos de idade, oferecendo 20 turmas de aproximadamente 25 alunos cada uma, divididas entre Jardim I, Jardim II, $1^{\circ}$ e $2^{\circ}$ ano do ensino fundamental.

De acordo com um levantamento feito na secretaria escolar, verificando as pastas de matrículas do ano 2015, se matricularam 537 estudantes, dos quais 182 moravam na cidade vizinha de Santa Elena de Uairén, o que representa mais de $30 \%$ dos estudantes da instituição.

Nesse contexto sociolinguístico complexo é que foi realizada a pesquisa. Com um público formado por estudantes venezuelanos que moram no Brasil, brasileiros residentes na Venezuela, brasileiros nascidos no Brasil, mas filhos de venezuelanos que atravessam a fronteira diariamente para estudar ${ }^{4}$ e filhos de casais das duas nacionalidades.

\section{Discussão e análise}

Concordando com Vieira (1995, p. 133), acredito que perante uma sociedade multicultural é necessário procurar políticas e comunicações interculturais e não apenas multiculturais, como geralmente acontece, onde as diferenças são fechadas em "ghettos", somente sendo reconhecidas suas particularidades e identidades próprias sem pelo menos colocá-las "[...] em pé de igualdade ao acesso à cidadania europeia, mundial, transnacional, transcultural". Essa transculturalidade que percebemos na fronteira Brasil/Venezuela é visível na escola, em qualquer atividade realizada em sala, ou fora dela, devido à diversidade cultural de brasileiros que moram na Venezuela, ou venezuelanos que nasceram e estudam no Brasil, até aqueles brasileiros que moram em Pacaraima e convivem com colegas do país vizinho.

Durante as observações participativas foi possível perceber que as salas de aulas vivem a transculturalidade, a partir do momento que interagem brasileiros que moram em Pacaraima cuja família é toda brasileira, com "brasileiros venezuelanos" e com brasileiros de família brasileira que residem na Venezuela. Alguns temas trabalhados na escola mostram a necessidade da educação intercultural, como o exemplo que narro a seguir, observado em uma aula da turma do Jardim II.

A professora perguntou: o que vocês gostam de comer em aniversários? O objetivo era colocar uma série de substantivos no quadro, propostos pelos alunos, para depois trabalhar com as vogais presentes em cada palavra. Ao perceber que ninguém respondia, a docente disse: quem gosta de brigadeiro?, nesse momento todos levantaram a mão. Depois, começaram a falar, muitos disseram piñata ${ }^{6}$, até os brasileiros de Pacaraima. Nesse momento, a docente achou estranho e não escreveu a palavra no quadro, mas depois de ouvir várias vezes, ela a incluiu na lista.

$\mathrm{Na}$ mesma atividade ainda escutei alguns alunos falando caramelo $^{7}$, chupeta $^{8}$ (alguns brasileiros que moram em Santa Elena/VE), outros coleguinhas acharam estranho, principalmente quando um deles falou chupeta, que em português é o artigo usado por bebês, mas em espanhol significa pirulito. Essas palavras não foram escritas no

\footnotetext{
${ }^{4}$ São as crianças denominadas "brasileiras venezuelanas”, ver Zambrano (2016).

${ }^{5}$ Grifo do autor

${ }^{6}$ A piñata é um boneco ou boneca, gigante, feito de papelão, muito popular nas festas infantis da América hispana. As pessoas colocam brinquedos pequenos e doces no seu interior, depois é pendurado e as crianças devem bater com um pau, cada criança bate, até que uma delas consegue derrubar ou quebrar o boneco, de onde saem os doces e brinquedos, momento em que todos correm parta tentar pegar o máximo possível no chão.

${ }^{7}$ Bala, bombom.

${ }^{8}$ Pirulito
} 
quadro, sendo desconsideradas e desperdiçando uma oportunidade de interagir na outra língua e na outra cultura. Dessa forma, a professora não só desrespeitou a cultura do outro, como manteve a cultura dominante como superior.

Nesse contexto multicultural, é necessário que a educação favoreça a interculturalidade, como afirma Candau (2008), respeitando a cultura do outro, pois o contexto é de identidades culturais distintas. Esse respeito é necessário na escola de fronteira e muitas vezes não acontece.

A professora Gisele ${ }^{9}$ afirmou que há um ponto positivo de ter alunos brasileiros e venezuelanos na turma, pela possibilidade adquirir novos conhecimentos. No entanto, naquela atividade a mesma docente deixou de lado os substantivos que os alunos falaram em espanhol e perdeu a oportunidade de adquirir e propiciar a aquisição de aprendizagem de novas palavras na língua espanhola. Por outro lado, o ponto negativo que a docente apontou foi a dificuldade com a comunicação, que segundo ela, não atrapalha o ensino e a aprendizagem, por serem crianças. Dessa forma, quando o profissional está disposto a trabalhar na interculturalidade aproveita cada situação de diferença linguística e cultural para ampliar o debate em sala de aula.

Por outro lado, Fleuri (2001) discute sobre a perspectiva intercultural, que segundo ele, emerge no contexto das lutas contra os processos crescentes de exclusão social. Assim, a perspectiva intercultural propõe novas estratégias de relação entre sujeitos e entre grupos diferentes. Busca promover a construção de identidades sociais e o reconhecimento das diferenças culturais.

A escola da cidade fronteiriça realiza várias atividades culturais no decorrer do ano escolar, dentro e fora da instituição, sendo que, a maioria foi observada para esta pesquisa. Em 2015 e 2016 teve arraial, teatro, amostra pedagógica com projetos, desfile de 7 de setembro, festa da páscoa, apresentação de danças como encerramento do ano letivo, atividades em alusão aos dias dos pais e das mães. Em todas essas atividades a participação dos estudantes de dupla nacionalidade, que residem do outro lado da fronteira, foi pequena.

$\mathrm{Na}$ apresentação de um baile típico no final do ano escolar de 2015, as "brasileiras venezuelanas" ficaram com vergonha e somente a Vitória dançou. A professora afirmou que não obriga nenhuma criança a participar.

Observei também que "brasileiros venezuelanos" preferem não participar do arraial. No primeiro ensaio, todos foram, mas aos poucos, as professoras iam tirando aquelas crianças que não gostavam, diziam que não queriam dançar, quase todos foram "brasileiros venezuelanos". Vitória participou dos ensaios, mas no dia do evento não compareceu, no ano anterior foi à festa junina, mas não dançou. No grupo de pais no whatsap, rede social usada pela professora para informar as novidades, uma mãe venezuelana não entendia do que a professora estava falando quando perguntou quais crianças queriam e podiam participar da quadrilha. A mãe perguntou em espanhol o que é a quadrilha. Só depois da explicação, disse que a fillha podia participar. Ela foi a única aluna "brasileira venezuelana" que dançou quadrilha, ainda um pouco tímida e com roupa diferente das outras meninas, mas se integrou na dança. Conforme Santos (2012, p. 6465), a escola como espaço de diferentes culturas deve desenvolver políticas que integrem essas diferenças:

[...] a escola como espaço de convivência de diferentes culturas, línguas e saberes, é possível supor que conflitos, conscientes ou inconscientes, entre esses diferentes grupos sociais podem ocorrer. Tais conflitos precisam ser geridos por este espaço de ensino e de aprendizagem, quer pela administração

${ }^{9}$ Os nomes são fictícios para preservar a identidade dos sujeitos. 
local da instituição escolar, quer por instâncias superiores. A escola como espaço de convivência de diferentes línguas, ou falares, é então um espaço no qual o desenvolvimento das políticas linguísticas se faz necessário. E como espaço de transmissão de conhecimentos, a escola torna-se um local privilegiado para as ações previstas no planejamento linguístico. (SANTOS, 2012, p. 64-65)

Para a autora, a mudança nas políticas linguísticas seria uma ajuda para superar esses problemas da escolarização em contexto multilíngue e multicultural.

Voltando à discussão sobre as atividades culturais, a professora Sheila afirmou que são poucos os que participam:

Saem, não querem, porém, aos poucos vão se integrando. (...) no início ficam tímidos, mas devagar, vendo os outros, vão começando a fazer também.

Prof. Sheila

No desfile de 7 de setembro de 2015 também se ausentaram os "brasileiros venezuelanos", apenas a Vitória estava presente. Embora a maioria dos pais dissesse em entrevista que o filho participa das atividades culturais da escola, não foi isso que observei. A atividade teatral dos três porquinhos foi a única da qual participaram quase todas as crianças, possivelmente porque nela não precisavam falar nem dançar, somente fazer os gestos.

De acordo com a professora Gisele, as crianças até querem comparecer, no entanto, os pais são pouco assíduos:

Os pais se evadem muito. Não vêm para o dia dos pais ou das mães (....), até para conversar com eles sobre as crianças é difícil, pois muitos não vão às reuniões.

Prof. Gisele

Como a docente afirmou, são poucos os pais que participam das atividades planejadas pela escola para homenageá-los e os que comparecem às reuniões de pais e mestres sempre são os mesmos. Geralmente, os pais dos alunos que têm mais dificuldades faltam. Devido à ausência dos responsáveis nessas atividades, fica ainda mais difícil o trabalho da escola no sentido de integrar todas as crianças, mas ao mesmo tempo, pode ser uma forma de respeitar as diversas culturas, já que a instituição não exige essa participação.

\section{Para finalizar}

Após toda a discussão realizada nesta análise, apresento a seguir, algumas considerações finais. Apesar da escola estar em contexto bilíngue multicultural e receber crianças que transitam em duas línguas e duas culturas, ainda falta muito para efetivamente realizar uma educação intercultural.

A língua portuguesa é a oficial e a cultura dominante é a brasileira, sendo assim, muitas crianças deixam de participar das atividades, pois quando tentam acrescentar algo 
da sua própria cultura, são banidas, mostrando que a relação entre discentes e docentes da instituição é regida pela cultura dominante, que em algumas situações deixa os alunos como estranhos na sala de aula.

A pesquisa mostrou que em 2015 quase $30 \%$ dos estudantes da escola moravam na Venezuela, dentre eles havia brasileiros, venezuelanos e brasileiros de nascimento com famílias venezuelanas. É uma "minoria” linguística, porém quantitativamente é um grupo que cada dia cresce mais na fronteira Brasil/Venezuela.

Os pais desses alunos, mesmo incentivando os filhos a estudarem no Brasil, muitas vezes faltam às reuniões e desvalorizam as participações em atividades culturais, desperdiçando as oportunidades de interagir com as culturas dos dois países fronteiriços.

Dessa forma, é necessário trabalhar a interculturalidade na escola de fronteira que nesse contexto transcultural, diariamente se depara com situações de multiculturalismo, com as quais a instituição deve aprender a lidar com respeito e profissionalismo.

\section{Referências}

ANDRÉ, M. E. D. A. Etnografia da prática escolar. 15 ed. Campina: Editora Papirus, 2008 .

BAUMAN, Z. O mal estar da pós modernidade. Tradução Mauro Gama. Rio de Janeiro: Jorge Zahar Ed., 1998.

Identidade: entrevista a Benedetto Vecchi. Tradução Carlos Alberto Medeiros. Rio de Janeiro: Jorge Zahar Ed., 2004.

BORTONI-RICARDO, S. M Reflexões teóricas que promovem o balizamento dos três conceitos chave: transculturalidade, linguagem e educação. In: CAVALCANTI, M. C \& BORTONI-RICARDO, S. M. (orgs). (2007) Transculturalidade, linguagem e educação. Campinas, SP. Mercado das letras, p. 07-19.

2008 .

O professor pesquisador: introdução à pesquisa qualitativa. São Paulo: Parábola,

CANDAU V. M. Multiculturalismo e educação: desafios para a prática pedagógica. In. MOREIRA, Antônio Flávio Barbosa; CANDAU, Vera Maria (Orgs.) Multiculturalismo: diferenças culturais e práticas pedagógicas. $2^{\mathrm{a}}$ ed. Petrópolis, RJ: Vozes, 2008.

COX e ASSIS PETERSON. Trasculturalidade e transglossia: para compreender o fenômeno das fricções linguístico-culturais em sociedades contemporâneas sem nostalgia. In: Cavalcanti e Bortoni-Ricardo (orgs). (2007). Transculturalidade, linguagem e educação. Campinas, SP. Mercado das letras, p. 23-43.

FLEURI, R. M. Multiculturalismo e interculturalismo nos processos educacionais. Rio de Janeiro: Vera (Org), 2001.

FLEURI, R. M. (Org.). Educação intercultural: mediações necessárias. Rio de Janeiro: DP\&A, 2003. 
FREITAS, D. B. A. A construção do sujeito nas narrativas orais. In: MARCUS, J.M \& CARVALHO, E. S. (orgs). CLIO Revista de pesquisa histórica. Recife: Ed. Universitária da UFPE, p. 92-107, 2008.

HALL, S. A identidade cultural na pós-modernidade. $11^{\text {a }}$ edição. Rio de Janeiro: DpeA Editora, 2006.

LAGARES, X. C. Identidade e (in) definição linguística: Galego e/ou português. In: Moita Lopes; Bastos. (Orgs.). Para além da identidade. Fluxos, movimentos e trânsitos. 1ed.Belo Horizonte: Editora UFMG, 2010, p. 129-149.

MOITA LOPES, L. P. Identidades fragmentadas: a construção discursiva de raça, gênero e sexualidade em sala de aula. Campinas, SP: Mercado de Letras, 2002.

. Por uma Linguística Aplicada Indisciplinar. São Paulo: Parábola editorial, 2006.

RAJAGOPALAN, K. O conceito de identidade em linguística: é chegada a hora para uma reconsideração radical. In: Inês Signorini (org). Lingua(gem) e identidade: elementos para uma discussão no campo aplicado. Campinas, SP: Mercado das Letras, 1998. p. 2145 .

. Por uma linguística crítica: linguagem, identidade e a questão ética. São Paulo: Parábola Editorial, 2003.

SANTOS, A. S. Multilinguismo em Bonfim/RR: o ensino de Língua Portuguesa no contexto da diversidade linguística. Tese de Doutorado. Departamento de Linguística, Português e Línguas Clássicas do Instituto de Letras da Universidade de Brasília - UnB, 2012.

SIGNORINI, I. "Do residual ao múltiplo e ao complexo: o objeto da pesquisa em Linguística Aplicada". In: SIGNORINI, I. e M. C. CAVALCANTI (orgs.) Linguística Aplicada e Transdisciplinaridade: Questões e Perspectivas. Campinas: Mercado de Letras, 1998. p. 89-98.

SILVA, T. T. A produção social da identidade e da diferença. In: SILVA, T. T. (org.). Identidade e diferença. A perspectiva dos Estudos Culturais. Petrópolis: Editora Vozes, 2009. p. 73-102.

STURZA, E. Línguas de fronteira: o desconhecido território das práticas lingüísticas nas fronteiras brasileiras. Revista Ciência e Cultura. São Paulo. Ano 57, n. 2, p. 47-50. abr./maio/jun. 2005.

Espaço de enunciação fronteiriço e processos identitários. Campinas: Proposições, v. 21, n. 3 (63), p. 83-96, set./dez.2010.

TEIXEIRA, C. S e RIBEIRO, M. A. A. Perspectiva intercultural no ensino de línguas. Revista Litteris: n. 9, p. 283-294, 2012.

VIEIRA, R. Mentalidades, Escola e Pedagogia Intercultural. In Revista Educação, Sociedades \& Culturas, Edições Afrontamento, Porto, n. ${ }^{\circ}$ 4, p.127-147, 1995. 
Recebido em 17 de setembro de 2018

Aceito em 14 de dezembro de 2018 